\section{Sub-cellular Distribution of 5-Hydroxytryptamine in Guinea Pig Brain}

Inouye, Kataoka and Shinagawa ${ }^{1}$ have recently criticized, by implication, my work on the sub. cellular distribution of 5-hydroxytryptamine $(\mathrm{HT})$ in guinea pig brain ${ }^{2}$. I do not agree that my assays were significantly interfered with by substance $P$. The reasons for this are as follows.

(1) The rat fundus strip was found to be relatively insensitive to substance $P(1 \mu \mathrm{g} H \mathrm{HT}$ was equivalent to 2,500, instead of $570 \mathrm{U}$. substance $P$ ) and the rosponse was qualitatively different: substance $P$ gave a rapid contraction followed by a fall in tonus during tho 30 -sec period of application of the drug, while HT gave a slower contraction which was not complete in $30 \mathrm{sec}\left(\mathrm{cf}\right.$. Vane $\left.{ }^{3}\right)$. The contraction produced by the brain extracts resembled that of HT. More recent work by Miss J. Cleugh ${ }^{4}$ shows that homogenates of the whole brain of guinea pigs contain 50-100 $\mathrm{v}$. substance $P / \mathrm{g}$ tissue when assayed on the fowl rectal cxcum ${ }^{5}$ in the presence of blocking agents for HT and other interfering substances. The H'T content of my guinea pig brain homogenates was $442 \pm 187 \mathrm{ng} / \mathrm{g}$ in 11 experiments. This compares with Correale's ${ }^{6}$ figures of $200-500 \mathrm{ng} / \mathrm{g}$ for guinea pig brain. Amin, Crawford and Gaddum's figures?, referred to by Inouye et al., are here irrelevant, being for the dog.

Thus, taking the best and worst situations (lowest substance $P$ content with highest HT content, and vice versa) 3-16 per cent of my total HT activity might theoretically have been due to substance $P$. In practice, in the doses used for assay, the amount of substance $P$ present would have been below threshold.

(2) Although HT was usually assayed on brain preparations heated at $100^{\circ}$ and $p \mathrm{H} 4$ for $10 \mathrm{~min}$ to release bound HT, the results were checked against the acetone extraction procedure of Baker $^{8}$ modified from that of Amin et al. ${ }^{7}$. The results agreed with the simpler acid extraction method within the error of the assay method.

(3) The HT contents of the brain homogenate and fractions were very low when prepared from animals pre-treated with reserpine.

(4) Baker', using the rat fundus strip, found essentially the same distribution of HT in brain fractions as I did; this is in contrast to her own earlier results with duodenum ${ }^{10}$. Michaelson and $\mathrm{I}^{11}$ have checked the earlier results using the spectrofluorophotometric method and have obtained essentially the same results, with, however, less variation from one experiment to another. We found the same distribution in untreated animals and animals treated with iproniazid, a monamine-oxidase inhibitor; in the latter, the absolute concentration of HT in the various fractions, including the nerve-ending fraction, was, as would be expected, more than twice as high as that in the untreated animals. A detailed account of this work is in preparation. Potter and Axelrod $^{12}$ have confirmed the localization of hydroxytryptamine in the presynaptic-vesicle-containing norve-ending fraction ${ }^{13}$ using the fluorophotometric method.

Regarding the stability of endogenous and added HT, my results showed ${ }^{2}$ that both endogenous and added HT were stablo in the presence of intact brain particles but were rapidly destroyed when the preparation was treated with ether. This destruction was inhibited by iproniazid $\left(10^{-4}-10^{-3} \mathrm{M}\right)$. The brain particle preparation in question contained some microsomes.

Apart from possible species differences, it is difficult to give a rational explanation of the dis. crepancy between my findings and those of Inouye et al:; however, in the light of subsequent results obtained in my laboratory and olsewhere, I do not feol inclined to modify my conclusion that HT in guinea pig brain is localized in the pre-synaptic vesicle-containing nerve-ending fraction, and that the dense type of storage particle found in duodenum does not occur in this brain.

\section{P. WhitTAKeR}

Biochemistry Department, Agricultural Research Council

Institute of Animal Physiology,

Babraham,

Cambridge.

'Inouve, A., Kataoka, K., and Shinagawa, J., Vature, 194, 286 (1962).

${ }^{2}$ Whittaker, V. P., Biochem. J., 72, 694 (1959).

${ }^{3}$ Vane, J. R., Brit. J. Pharmacol., 12, 344 (1957).

‘ Cleugh, J. (personal communication).

${ }^{3}$ Cleugh, J., Gaddum, J. H.. Holton, P., and Leach, I., Brit. J.

- Correale, P., J. Neurochem., 1, 22 (1957).

Amin, A. H., Crawford, T. B. B., and Gaddum, J. H., J. Physiol.

'Baker, R. V., J. Physiol., 142, 563 (1958).

- Baker, R. V., thesis, University of Oxford (1959).

${ }^{10}$ Baker, R. V., J. Physiol., 145, 473 (1959).

"Michaelson, I. A., and Whittaker, V. P., Biochem. Pharmacol., 11,

${ }^{12}$ Potter, L. T., and Axelrod, J., Nature, 194, 581 (1962).

${ }^{13}$ Gray, E. G., and Whittaker, V. P., J. Anat. (Lond.), 96, 79 (1962),

\section{Metabolism of Rose Bengal}

Rose bengal has been used for chromo-excretion liver tests usually without a more accurate investigation of the composition of the dye. From the results of Stowe et al. ${ }^{1}$, it appears that only highly halogenated derivatives of fluorescein are selectively excreted by the liver. It is important to use a pure preparation which does not contain less-halogenated derivatives. Recently, a number of authors ${ }^{2-4}$ directed attention to the heterogeneous character of commercial preparations, but only Bocci ${ }^{4}$ isolated pure rose bengal (tetrachlorotetraiodofluorescein) by paper chromatography and used it for investigations in metabolism. Recent publications ${ }^{3-5}$ indicate that rose bengal is not metabolized by the organism and is not transformed into other derivatives which can bo detected by paper chromatography.

Since it is difficult to use paper chromatography for obtaining pure substance on a large scale. wo used adsorption chromatography on alumina ${ }^{6}$. Commercial rose bengal (Geigy), dissolved in 96 per cent ethanol, was applied, and for the elution the same solvent was used, whereby a separation into ton dyes was obtained. Moreover, we investigated the dye which was eluated as the second from the column. It had an absorption maximum at $550 \mathrm{m \mu}$. a molar extinction coefficient of 99,120 and elementary analysis corresponded to tetrachlorotetraiodofluorescein. Labelling with iodine-131 as described by Liebster and Andrysek was adopted, with a 70 per cent radioactivity yield and labelled rose bengal was purified by removal of the traces of inorganic iodide iodine-131 by repeated precipitation.

This preparation was administered intravenously to rats in amounts of $1-20 \mu \mathrm{c}$. por animal. In the 